\title{
Modeling simulation and experiments for direct operated relief valve
}

\author{
Li Yang ${ }^{1, a}$, GuangFeng Guan ${ }^{1, b}$, Qingjun Lv ${ }^{2, c}$, Qinghui Xiong ${ }^{2, d}$, \\ Wenqi Ma ${ }^{1, e^{*}}$,Wei Xiong ${ }^{1, f}$, \\ ${ }^{1}$ Ship Electromechanical Equipment Institute, DaLian Maritime University, China \\ ${ }^{2}$ China North Vehicle Research Institute, Beijing, China \\ ayanglidlmu@126.com, bgfguan@126.com, c15901337363@163.com, 'qhxiong@163.com, \\ e1743174442@qq.com, ${ }^{f} x w 2512 @ 139 . c o m$
}

Keywords: Direct Operated Relief Value, Influence Parameters, Optimization, Static And Dynamic Simulation, Static And Dynamic Experiment.

Abstract. Hydraulic Component Design hydraulic components design library offered by AMESim was used to simulate the internal structure and working principle of direct operated relief valve. The influence of spring stiffness, spring pre-tightening force, spool weight and damping hole diameter on direct operated relief valve dynamic characteristics were analysised. The process parameters of existing relief valve can be optimized by this investigation. The direct operated relief valve static and dynamic characteristic experiment were carried out on transmission device oil supply system experimental table. Simulation and experiment results came to an agreement and it proved the correctness of the model built. Providing a strong support for design and selection of relief in the future.

\section{Introduction}

The working principle of direct relief valve is: pressure oil acts on the valve core directly and keep balance with spring force so that the valve core can be controlled to be open and close ${ }^{[1]}$. Relief valve is used in vehicle hydraulic system wildly. It often acts as constant pressure valve to overflow the excess fluid in the system and keep the inlet pressure constant. It is a key part in vehicle hydraulic system $^{[2]}$. It is necessary to investigate the dynamic performance of relief valve in vehicle hydraulic system.

AMESim is systems engineering advanced modeling and simulation platform. Users can build complex field model of multidisciplinary system in the same platform ${ }^{[3]}$. There is Hydraulic Component Design in AMESim, users can design hydraulic component and simulation based on demand.

Structure and working principle of a kind of relief valve are introducted in this novel. The structure must be expressed in combination of several components not a single one. The static and dynamic characteristic are simulated in this novel and simulation and experiment result is compared. The influence of spring stiffness, spring pre-tightening force, spool weight and damping hole diameter on direct relief valve dynamic characteristics are analysised. It provides a strong support for design and selection of relief in the future. 


\section{Structure and working principle of relief valve}

The structure of vehicle relief valve is shown in Fig.1.

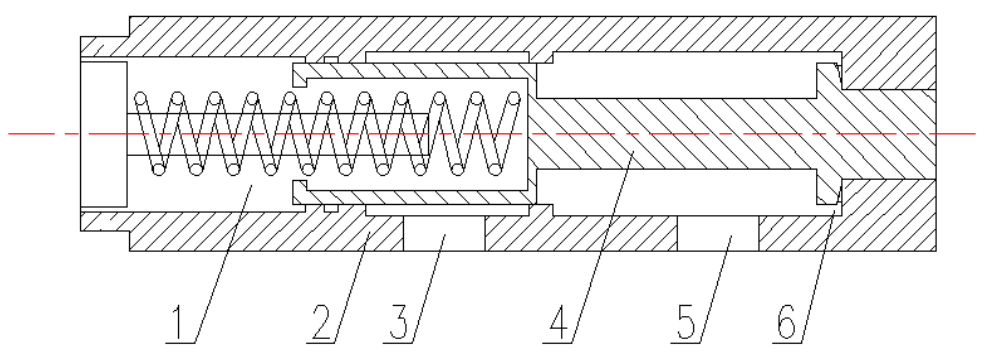

1- Spring 2-Valve body 3-Outlet 4- Valve Core 5- Inlet

6- Damping hole

Fig. 1. Structure of relief valve

It is composed of spool, valve bush and spring. The relief valve is closed when do not work. The oil flow from relief valve inlet, through damping hole and impact at right wall of spool. When the inlet pressure is low, the force impacting at right wall of spool is less than spring pre-tightening force, the relief valve still is closed. When the inler pressure increases, the force impacting at right wall of spool is greater than spring pre-tightening force, the relief valve is opened. When two forces above is balanced, the relief valve is steady.

\section{Modeling of relief valve in AMESim}

The simulation model of relief valve is shown in Fig.2.

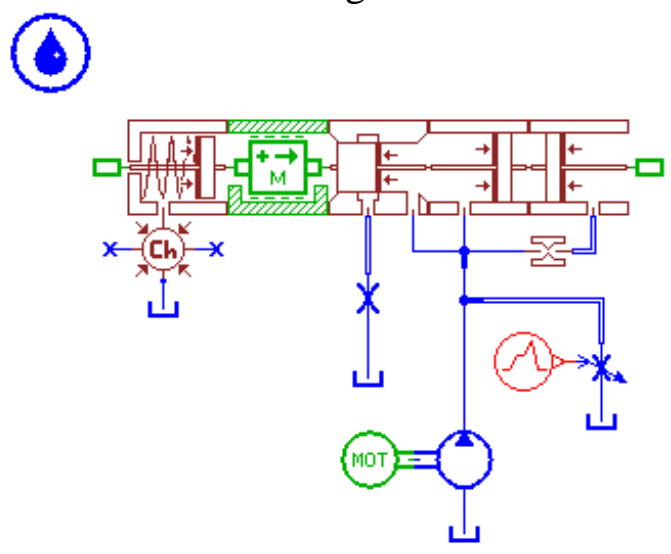

Fig.2 The simulation model of relief valve

Hydraulic Component Design in AMESim is used to simulate the structure of relief valve. AMESim is easy to understand ${ }^{[4]}$. The influence of compressibility, leakage of oil, frictional force of spool, resistance of channel, the volume of a pressure vessel and flow change due to volume change in some small vessel are ignored in model above ${ }^{[5]}$. All of the pressure walls are simulated by component in Hydraulic Component Design in AMESim according to the relief valve structure. Based on real engineering demand, the pressure range is $2 \pm 0.2 \mathrm{MPa}$.

\section{Simulation result and analysis}

The dynamic characteristic of relief valve is process that system pressure controlled by valve changes with time when flow step change. It is a important parameter to measure the valve performance ${ }^{[6]}$. The factors that affect on dynamic quality are complex, the major one is structure parameter itself.

Influence of spring stiffness. Reasonable spring stiffness is conducive to improve the on-off characteristic and pressure stability of relief valve. Choosing spring stiffness as k=8 N/mm, 18 
$\mathrm{N} / \mathrm{mm} 、 28 \mathrm{~N} / \mathrm{mm}$ respectively and simulating the overflow valve under the condition of invariable load, relief valve inlet pressure changing with time curve is shown in Fig.3.

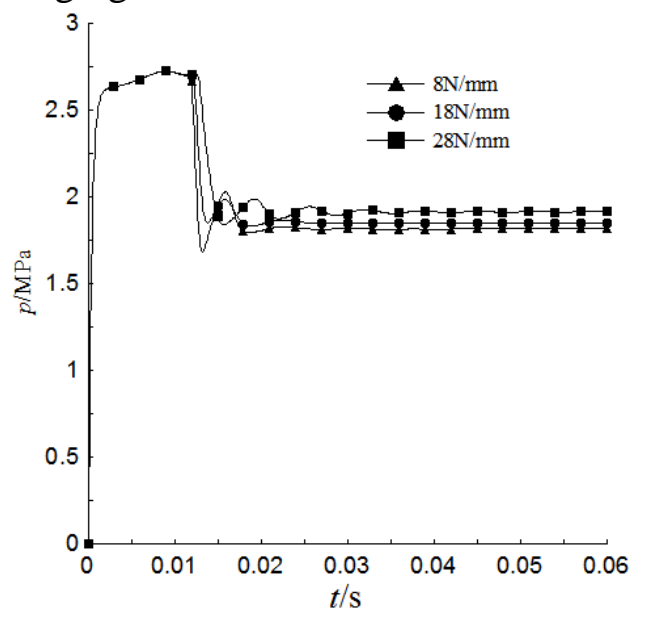

Fig.3 Inlet pressure changing with time curve for different spring stiffness

In Fig.3, spring stiffness has an influence on steady pressure of relief valve. The bigger the spring stiffness is, the bigger the inlet steady pressure. The reason is that when the opening is same, the force increases as the spring stiffness increases. This results in that the fluid pressure impacting on spool increases. When the spring stiffness is too much bigger, such as $\mathrm{k}=28 \mathrm{~N} / \mathrm{mm}$, the inlet pressure steady time is long and the dynamic characteristics become worse. At the same time, the influence of spring stiffness on dynamic characteristics is little.

Influence of spring pre-tightening force. Choosing spring pre-tightening force as $\mathrm{F}=430 \mathrm{~N}$, $470 \mathrm{~N} 、 510 \mathrm{~N}$ respectively and simulating the overflow valve under the condition of invariable load, relief valve inlet pressure changing with time curve is shown in Fig.4.

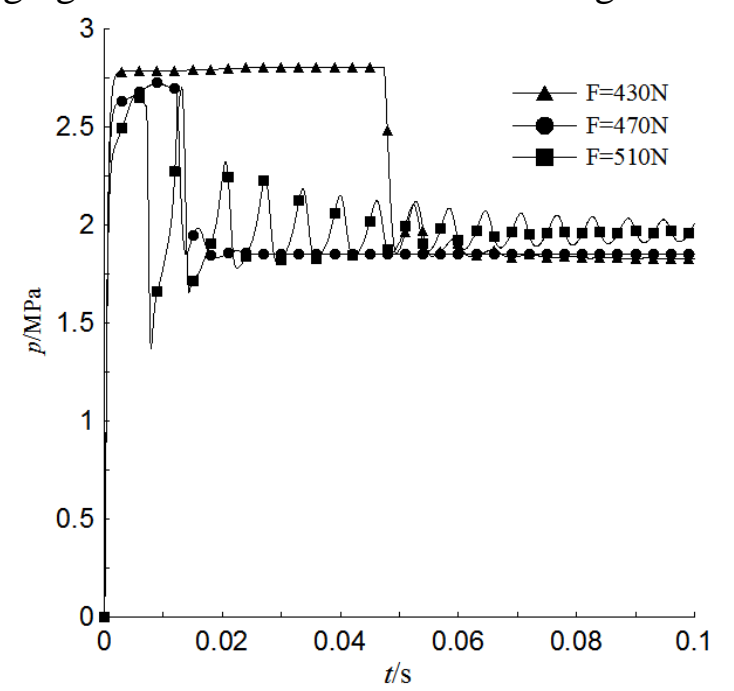

Fig.4 Inlet pressure changing with time curve for different spring pre-tightening force

As shown in Fig.4, spring pre-tightening force has a great influence on dynamic characteristics. If the spring pre-tightening force is too big or small, the transition time increases obviously, different degree of oscillation occurs meanwhile. The pressure overshoot amount changes with spring pre-tightening force. Spring pre-tightening force should be determined by dynamic characteristics.

Influence of spool weight. To investigate the influence of spool weight on outlet pressure. Spool weight is selected as $m=0.18 \mathrm{~kg}, 0.28 \mathrm{~kg} 、 0.38 \mathrm{~kg}$ respectively. The load is steady. Inlet pressure changing with time curve is shown in Fig.5. 


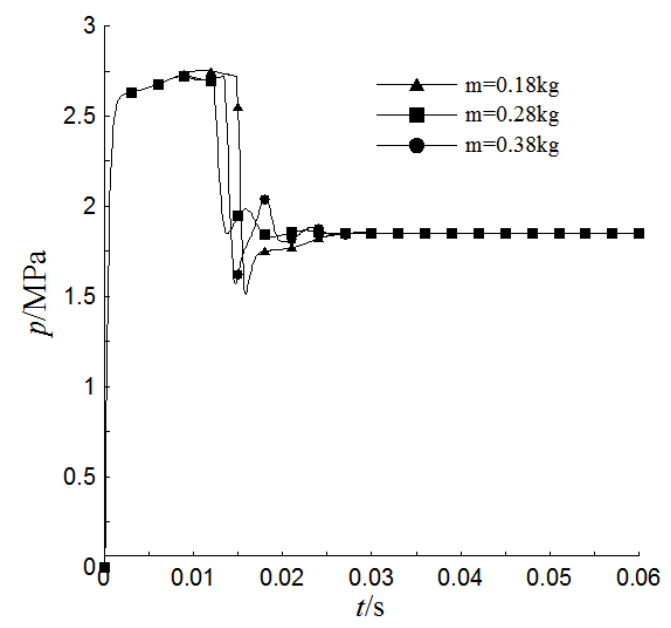

Fig.5 Inlet pressure changing with time curve for different spool weight

As shown in Fig.5, different spool weight have a weak influence on dynamic characteristics of relief valve. At the same time spool weight has nothing to do with steady pressure. In the end, the pressure is steady at $1.8 \mathrm{MP}$.

Influence of damping hole diameter. Choosing damping hole diameter as $D=1 \mathrm{~mm}, 2 \mathrm{~mm} 、 3$ $\mathrm{mm}$ respectively and simulating the overflow valve under the condition of invariable load, relief valve inlet pressure changing with time curve is shown in Fig.6.

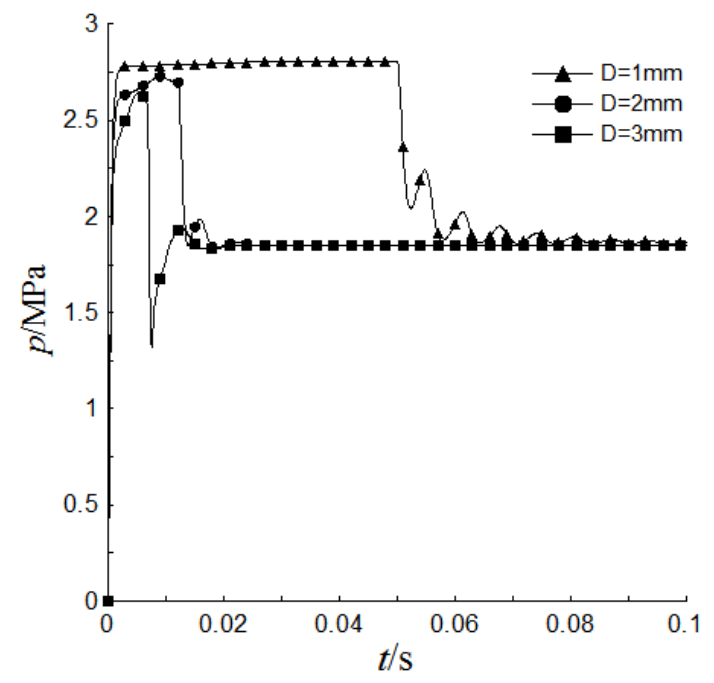

Fig.6 Inlet pressure changing with time curve for different damping hole diameter

In Fig.6, if the damping hole diameter changes, the inlet steady pressure is constant. But the steady time and pressure overshoot amount are different. When the damping hole diameter is smaller, the inlet pressure overshoot amount is lager, the time before steady is longer, the dynamic characteristics is worse. When the damping hole diameter is quite great, large degree of oscillation occurs, damping hole diameter should be determined by dynamic performance. 


\section{Experiment investigation of relief valve}

Experiment principle of relief valve. The principle of experiment experimental table is shown in Fig.7.
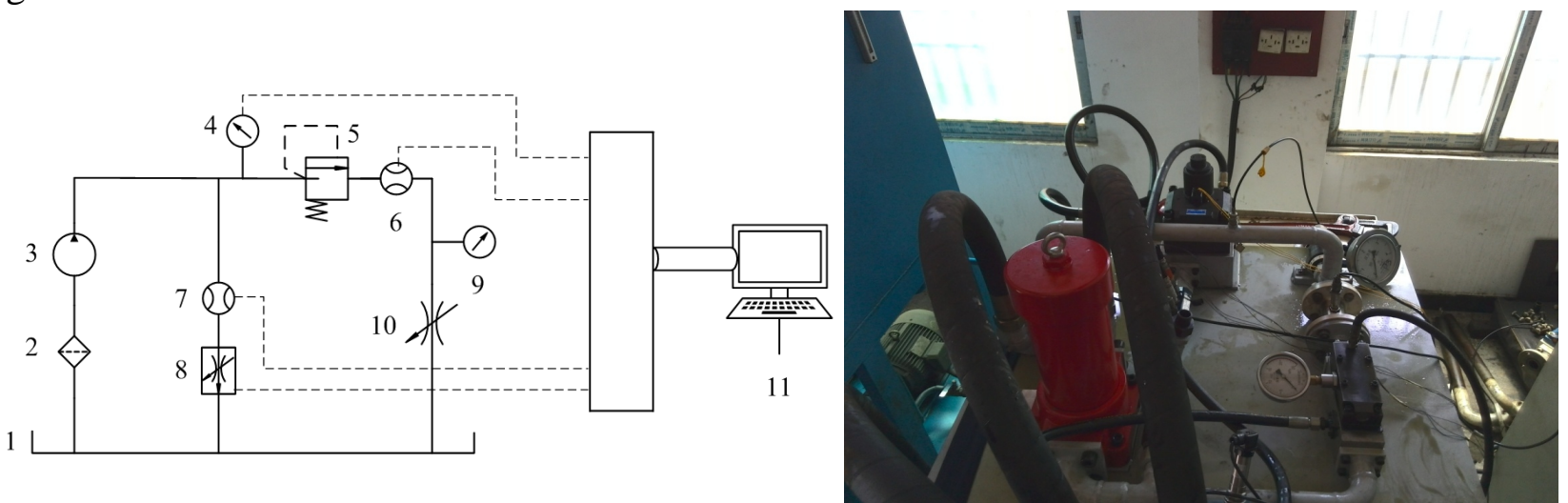

1- Oil tank 2- Filter 3- Pump 4- Pressure sensor 5- Relief valve measured

6- Flow sensor 7- Flow sensor 8- Proportion throttle valve 9- Pressure gauge

10- MG type variable throttle valve 11-Computer

Fig.7 The principle of experiment experimental table

Pressure test point is set at relief valve inlet in this experimental table. Value can be obtained by pressure sensor. Turbo flow sensor is linked at outlet to measure the overflow. MG type variable throttle valve is linked after flow sensor to simulate the load at outlet in real transmission device. There is a pressure gauge at outlet to measure the pressure value at inlet of MG type variable throttle valve. Proportion throttle valve and relief valve is connected parallel to simulate load. Flow sensor and pressure sensor are set before proportion throttle valve to measure the pressure and flow of oil channel.

Compare of experiment and simulation results. In experiment, the pump speed is $1000 \mathrm{r} / \mathrm{min}$, displacement is $270 \mathrm{ml} / \mathrm{r}$. On-off and pressure-flow characteristics can be obtained by calculating the experiment data. Meanwhile, AMESim is used to simulated based on experiment situation. The simulation and the experiment results are compared in Fig.8.

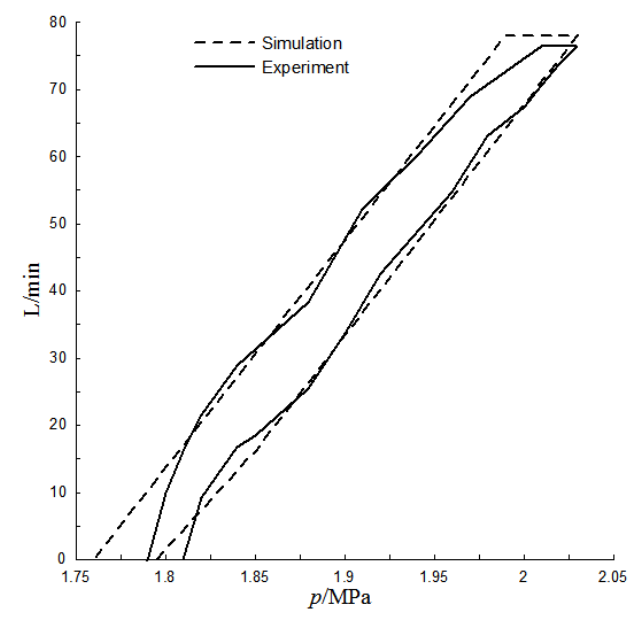

Fig.8 On-off characteristics curve

As shown in Fig.8, relief valve is opened at $1.81 \mathrm{MPa}$ and closed at $1.78 \mathrm{MPa}$. The opening pressure and closing pressure is close. It shows that the on-off characteristics is great. When the load is maximum, the overflow also is $75 \mathrm{~L} / \mathrm{min}$. When the overflow is maximum and the load decreases, there is insensitive area that the inlet pressure decreases with the load decreasing, but the overflow is constant. The experiment and simulation results almost the same. It proves that the simulation model is correct. 
To investigate the dynamic characteristics of relief valve, the control voltage of proportion throttle valve is changed to increase or decrease the load suddenly to regulate the relief valve from close to open and then to close. The dynamic characteristics of relief valve is obtained in Fig.9.

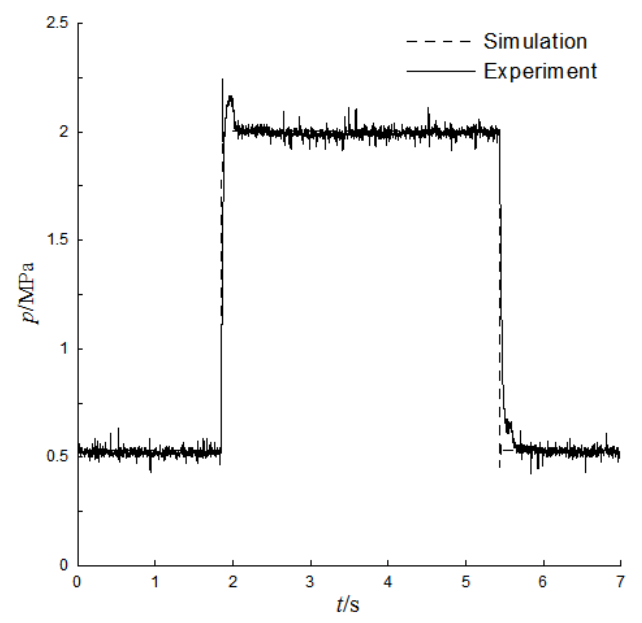

Fig.9 The dynamic characteristics of relief valve curve

In comparison between simulation and experiment, two curves come to an agreement. Even when the relief valve is opened, simulation curve conforms to experiment curve successfully. It also proves that the simulation model is correct.

\section{Conclusions}

According to the simulation of spring stiffness, spring pre-tightening force, spool weight and damping hole diameter of direct relief valve, it can be concluded that the most major factors are spring pre-tightening force and damping hole diameter, the second is spring stiffness, spool weight almost has no influence.

Damping hole diameter and spring pre-tightening force have an influence on dynamic characteristics of relief valve, especially transition time. Spring pre-tightening force has certain influence on steady pressure. But damping hole diameter almost has no influence on it.

Comparison between experiment and simulation results proves the correctness of model built. Meanwhile the simulation model also has a guidance to experiment. It provides reliable basis for relief valve design and choose in the future.

\section{References}

[1] Zhuangyun Li, Hydraulic components and systems, third ed., BeiJin, Machinery Industry Press. 2012. "In Chinese"

[2] Xiaokong Liu, Jiale Li, Weibiao Ye, Yong Li. Present situation and Prospect of hydraulic valve of construction machinery in China, Machine Tool \& Hydraulics. (2012) 144-146. "In Chinese"

[3] Xuan Yu, Haihong Chen, Yu Zheng, Modeling and simulation analysis of pressure relief valve based on Amesim, Hoisting transport machinery. 10(2011) 32-35. "In Chinese"

[4] Chengtong Sun, Guohua Chen, Xuehua Jiang, Hu Han, Hydraulic system simulation technology and simulation software research, Machine Tool \& Hydraulics.(2008) 36. "In Chinese"

[5] Yongjun Gong, Wei Xie, Hua Zhou, etal, Experimental study on the water hydraulic unloading relief valve, Chinese Hydraulics \& Pneumatics. 9(2005) 58-59. "In Chinese"

[6] Xiaofeng He, Haiyang He, Yinshui Liu, etal, Numerical simulation on the dynamic characteristics of a two-stage water hydraulic relief valve, Chinese Journal of Mechanical Engineering. 1(2006) 76-80. "In Chinese" 